\title{
BMJ Open Evaluating sexual health in sex workers and men who have sex with men: the SMESH cross-sectional protocol study
}

To cite: Wendland EM, Bessel M, Comerlato J, et al. Evaluating sexual health in sex workers and men who have sex with men: the SMESH cross-sectional protocol study. BMJ Open 2019;9:e031358. doi:10.1136/ bmjopen-2019-031358

- Prepublication history for this paper is available online. To view these files, please visit the journal online (http://dx.doi. org/10.1136/bmjopen-2019031358).

Received 29 April 2019 Revised 24 September 2019 Accepted 30 0ctober 2019

Check for updates

(C) Author(s) (or their employer(s)) 2019. Re-use permitted under CC BY-NC. No commercial re-use. See rights and permissions. Published by BMJ.

${ }^{1}$ Escritório de Projetos PROADISUS, Hospital Moinhos de Vento, Porto Alegre, Rio Grande do Sul, Brazil

${ }^{2}$ Department of Public Health, Universidade Federal de Ciencias da Saude de Porto

Alegre, Porto Alegre, Rio Grande do Sul, Brazil

${ }^{3}$ Department of STIs, AIDS and Viral Hepatitis, Ministry of Health, Brasilia, DF, Brazil

${ }^{4}$ National Immunization Program, Ministry of Health, Brasilia, DF, Brazil

Correspondence to Dr Eliana Marcia Wendland; elianawend@gmail.com

\section{ABSTRACT}

Introduction Human papillomavirus (HPV) infection is transmitted through skin-to-skin contact, and vaginal and anal sex are the most common transmission routes. Sex workers and men who have sex with men (MSM) are more exposed to the virus, and therefore, a higher frequency of this infection would be expected. The prevalence of HPV infection types and the forms and factors of transmission must be investigated to control infection-related outcomes. This protocol study will be the first nationwide study with a uniform methodology to evaluate HPV prevalence of and infection types among sex workers and MSM in Brazil. Methods and analysis This multicentre cross-sectional study will be conducted with a respondent-driven sampling method to recruit 1174 sex workers and 1198 MSM from all regions of Brazil. The study will consist of preliminary interviews to verify the eligibility criteria and characterise the network size as well as a second questionnaire to obtain sociodemographic, behavioural and sexual information. Specimens from the oral cavity and anal and cervical or penile/scrotal sites will be collected. All HPV samples will be processed in a certified central laboratory. Other sexually transmitted infections will be evaluated by interview and by rapid testing for HIV and syphilis. Strict quality control will be conducted using different procedures, including the training and certification of the health professionals responsible for acquiring data and monitoring visits.

Ethics and dissemination The project was approved by the research ethics committee of the main institution and the corresponding ethics committees of the recruitment sites. Due to the literature gap on the sexual health of sex workers and MSM and the intense stigma surrounding these populations, a critical analysis of the study results will contribute to epidemiological knowledge and will be useful for the development of strategies against virus morbidities.

\section{INTRODUCTION}

The association between certain oncogenic strains of human papillomavirus (HPV) and cervical cancer, as well as some oropharyngeal, vulvar, vaginal, penile and anal cancers, has been well established. ${ }^{1}$ Despite the declining cervical cancer rates in many
Strengths and limitations of this study

- This is a nationwide, multicentre study with sex workers and men who have sex with men.

- Human papillomavirus (HPV) genotyping is performed at different sites, in oral, genital and anal regions.

- The study uses respondent-driven sample methodology that is appropriate for sampling a hard-toreach population.

- The sampling is restricted to state capitals and does not include a qualitative approach.

- The Sex Workers and Men Who Have Sex with Men: Evaluation of Sexual Health study combines analyses of HPV, syphilis and HIV prevalence and sexual health.

populations worldwide, ${ }^{2}$ the incidence of other HPV-related cancers is rising among both men and women. ${ }^{3}$ Although the reasons for this increase in incidence are unclear and deserve further investigation, possible factors include changes in sexual behaviours (ie, number of lifetime sex partners, unprotected oral sex and receipt of anal sex). ${ }^{3}$

HPV is transmitted through skin-to-skin contact, with vaginal and anal sex being the most common transmission routes. ${ }^{4}$ Sex workers ${ }^{5}$ and men who have sex with men $(\mathrm{MSM})^{67}$ are more exposed to the virus than other individuals in the general population and are disproportionately affected by other sexually transmitted infections (STI). ${ }^{8}$ A higher frequency of HPV infection would be expected, and although studies have found a higher association, research has produced conflicting results. ${ }^{5-11}$

Sex workers constitute an epidemiologically important group for HPV infection because they may acquire this infection and transmit it to other sexual partners. However, female sex workers seem more aware of 
prevention strategies and more up to date on cervical cancer screening than non-female sex workers. ${ }^{10}$ It is known that the overall HPV prevalence is high in this population, affecting approximately $42.7 \%$ of female sex workers (with a range of $2.3 \%$ to $100 \%$ ), ${ }^{12}$ but little is known about HPV prevalence in Brazil. ${ }^{13}$ Regarding male sex workers (MSW), information characterising their practices, the contexts where they live and their needs is very limited. To our knowledge, only one study has examined HPV in MSW. This study was conducted in Vietnam with 654 MSW (aged 16-35 years) and found the prevalence of genital HPV to be $33 \% .{ }^{14}$ Most MSW offer sex to men rarely identify as sex workers, using local or international terms instead. ${ }^{15}$

MSM also have a high risk of HPV infection and HPVrelated disease than men who have sex with women, ${ }^{16}$ with the incidence of anal neoplasia being nearly 20 times higher in MSM. ${ }^{17}$ The lack of reliable data on the prevalence of HPV among these populations hampers the establishment of evidence-based intervention programmes. ${ }^{3}{ }^{11}$

The prevalence of HPV types, the forms of transmission and associated factors must be investigated to control the infection and related outcomes. This study is the first to adopt a nationwide scope with a uniform methodology to evaluate the prevalence of HPV and its infection types among sex workers and MSM in Brazil.

\section{OBJECTIVES}

\section{Primary objective}

To determine the prevalence of HPV in sex workers and MSM in Brazil.

\section{Secondary objectives}

- To investigate the prevalence of oral, genital and anal HPV among sex workers and MSM.

- To evaluate the main HPV types in each site for both populations.

- To identify behavioural factors associated with HPV infection and its infection types.

- To evaluate the association of HPV with other STI, including syphilis and HIV.

\section{METHODS AND ANALYSIS \\ Study design}

The Sex Workers and Men Who Have Sex with Men: Evaluation of Sexual Health (SMESH) study is a crosssectional, multicentre nationwide study that will adopt the respondent-driven sampling (RDS) method to recruit participants. All five regions of Brazil will be represented, each including at least two state capitals. Primary care units and centres for testing and counselling in each city will be selected based on their representativeness of the health districts and their resources for collecting and storing samples.

Eligible individuals are aged 18 years or older and have a valid peer recruitment coupon. They also need to be
- Self-identified as sex workers (male or female) who have engaged in commercial sex at least once in the previous 4 months (to assure recent sex work activity) OR

- Self-identified as MSM (gay, bisexual and other men who have sex with men) who have engaged in oral or anal sex with another man in the last 12 months.

The exclusion criteria will be as follows: being younger than 18 years old, being pregnant, having delivered a baby in the last 3 months, having undergone a hysterectomy or trachelectomy and having ever had cervical intraepithelial neoplasia grade 2 or higher will be considered ineligible for the study. Transgender participants will be excluded. There will be no exclusion based on HPV vaccination status; however, we will investigate whether the participants have been vaccinated and determine the number of doses taken, independent of how long it has been since the vaccination was received. Vaccinated individuals will be separately included in a sensitivity analysis.

The sample size (1174 sex workers and 1198 MSM) was calculated based on the estimated $42.7 \%$ prevalence of HPV in sex workers ${ }^{12}$ and $48.0 \%{ }^{18}$ in MSM. This sample size will allow us to estimate the prevalence of HPV within these groups with an alpha of $5 \%$, a power of $80 \%$, an acceptable variation of $4 \%$ and a design effect of 2 . The minimum number of participants per stratum (collection site) will be 100 .

\section{Sampling technique}

RDS is the most appropriate method among available alternatives for the inclusion of large and mostly hidden social networks of sex workers and MSM. ${ }^{19}$ RDS is a process in which seeds (initial participants) are utilised to recruit peers through waves of recruitment and allows for calculation of selection probabilities. The relationship between recruiters and recruits is documented so that recruitment biases can be adjusted and assessed in the analysis. ${ }^{19}$

The initial focus will be on well-connected sex workers and MSM in the community and those who report having extensive social networks during the preparatory survey within each city. The coupon colour will differentiate groups into sex workers (purple) or MSM (green). The study will be initiated with three seeds in each capital city selected to represent different sociodemographic and sexual characteristics within the sex workers and MSM communities (figure 1). Three coupons for each group will be distributed to each respondent to recruit others until the sample size has been reached and an equilibrium on key variables is achieved. ${ }^{19}$ Each coupon has a specific barcode to manage peer-to-peer recruitment. Sampling should result in long recruitment chains, whereby the final sample is not biased by the initial convenience sample of seeds. Incentives for study participation will consist of sexual health materials (male and female condom, lubricating oil) and financial reimbursement. Each participant will receive a primary incentive of $R \$ 40.00$ (40.00 Brazilian reals, the equivalent to 


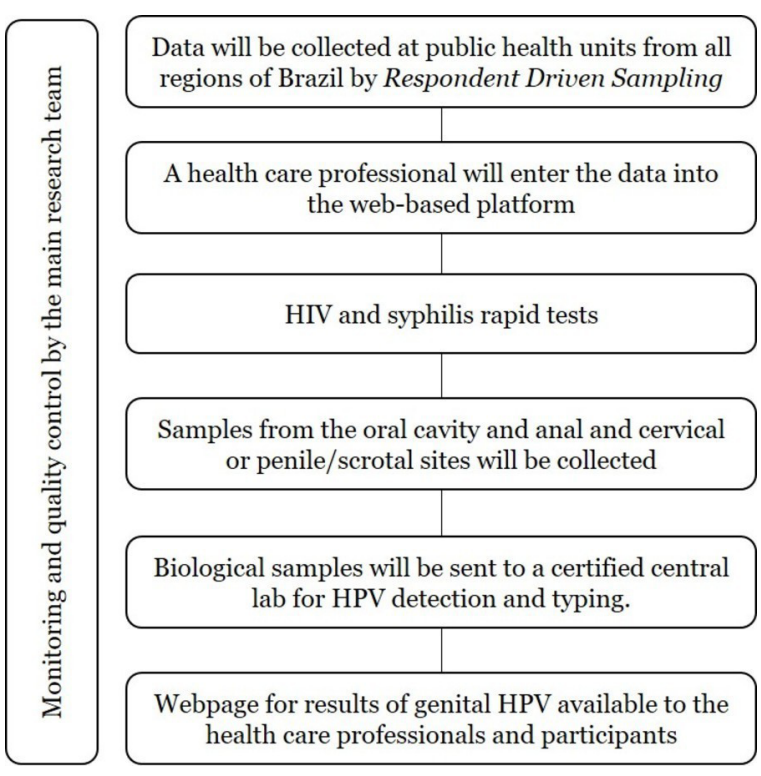

Figure 1 Logistics for the nationwide multicentre of data and specimens collection. HPV, human papillomavirus.

US $\$ 10.00$ ) and a secondary incentive of $\mathrm{R} \$ 30.00$ for each recruited participant who completes the survey. The reimbursement will be modest enough to prevent coercion.

\section{Measurements and biological samples}

The study will consist of a preliminary interview to verify the eligibility criteria and characterise the participant network size. First, participants will sign informed consent. The standard interview will be based on validated instruments and divided into sections (table 1). After the interview, samples from the oral cavity, anal cavity and cervical or penile/scrotal sites will be collected from each participant.

Oral samples will be obtained through 30 s mouthwash and gargle cycles using $10 \mathrm{~mL}$ of a standardised commercial mouthwash ${ }^{20}$ and will be stored in a $15 \mathrm{~mL}$ Falcon tube.

Cervical samples will be obtained by a healthcare professional using the Digene HC2 DNA Collection Kit (Qiagen). Cervical and anal samples will be placed in a transport tube containing $1 \mathrm{~mL}$ of a specimen transport medium.

Penile (penile shaft, glans penis/coronal sulcus and scrotum) samples will be obtained using a FloqSwabs (Copan) previously moistened with sterile saline solution. After collection, FloqSwabs will be stored in $2 \mathrm{~mL}$ of eNAT Preservation Medium for Nuclei Acids (Copan). Participants will be instructed by healthcare professionals and will receive illustrated schematic instructions for reference during penile self-collection.

\begin{tabular}{l} 
Table 1 Topics accessed in th \\
\hline Topics \\
Social network size \\
Identification of participant \\
and sociodemographic \\
variables \\
Smoking, alcohol and other \\
drugs \\
Female sexual and \\
reproductive health \\
Health
\end{tabular}

Sexual behaviour

\section{Specific content}

\section{Social network size. ${ }^{19}$}

Zip code, age; race/skin colour, ${ }^{39}$ relationship status, education level, ${ }^{40}$ last-month family income and the number of people dependent on this income, ${ }^{41}$ employment status, ${ }^{40}$ socioeconomic class. ${ }^{42}$

Current and past smoking habits, including quantity and frequency, ${ }^{43}$ use of alcohol ${ }^{44}$ and illicit drugs. ${ }^{45}$

Age of menarche; history of contraception, ${ }^{46}$ pregnancy and childbirth; use of contraceptive methods; Pap testing history and if so whether any alterations have ever been observed.

Health status classification ${ }^{47}$; STI knowledge and beliefs; history of STIs; STI testing, diagnosis, treatment and partner notification history; HIV testing history; pre-exposure prophylaxis knowledge and use; self-esteem ${ }^{48}$; body image perception; suspicious HPV-related lesions.

Sexual orientation; gender identity; age at first sexual intercourse; gender(s) of sexual partners; access to preventive activities and utilisation of health services; types of venues to meet sexual partners - public toilet, bars, saunas, parties and/or sex parties and different frequencies; sex work characteristics; sexual activities (eg, oral-genital performed/received, receptive and/ or insertive vaginal or anal sex, the number and types of sex partners will be separated into steady partners (sex partner(s) considered to be emotionally attached), casual partners (onenight-stand partners) and commercial partners (those exchanging sex for money or kind); the frequency of condom use for vaginal, anal and oral sex with the three types of partners will be assessed for the preceding 6-month period. Condom use will be ranked at four levels: never, sometimes (less than half of the occasions), frequently (more than half occasions) and always. How much participants know about HPV and vaccination (when and who must receive the vaccine). $^{49}$

knowledge

Adult abuse/trauma; Intimate partner violence; Victimisation and attribution; Physical symptoms due to victimisation.

HPV, human papillomavirus; STI, sexually transmitted infections. 
For the anal sample, the participants will be given other illustrated instructions on how to self-collect. The participants will be instructed to remove the swab from the Digene Female Swab Specimen Collection Kit, insert it $3 \mathrm{~cm}$ into the anal canal, rotate it $360^{\circ}$ at least twice and gently remove the swab afterwards. ${ }^{21}$ Healthcare professionals will remain available for assistance during the selfcollection procedures.

All biological samples will be maintained refrigerated between $2^{\circ} \mathrm{C}$ and $8^{\circ} \mathrm{C}$, and transported to a central laboratory in Porto Alegre to start the specimen processing. The temperature will be monitored with a data logger.

HIV and syphilis rapid tests will be performed using the finger prick test, ${ }^{22}$ except in the case of participants with a previous diagnosis of HIV. Individuals with prior syphilis infections will be invited to perform Venereal Disease Research Laboratory tests only if they do not have medical records from the last 3 months. All tests will occur before the interview, and all participants will receive pretest and post-test counselling. Participants who tested positive will be counselled and immediately referred to public health services for appropriate follow-up.

\section{Specimen processing}

The samples will be aliquoted and stored at $-80^{\circ} \mathrm{C}$ until genotyping. DNA will undergo automated extraction using magnetic beads for isolation and purification by the MagNA Pure LC 2.0 Instrument (Roche Molecular Systems) and the LC Total Nucleic Acid Isolation Kit-High Performance following the manufacturer's instructions.

HPV detection and genotyping will be performed using the Novaplex II HPV28 Detection (Seegene, Seoul, South Korea) which is based on a multiple real-time PCR assay that can differentiate the target nucleic acid between 27 HPV types. The test detects HR-HPV types $(16,18,26,31$, $33,35,39,45,51,52,53,56,58,59,66,68,69,73$ and 82 ) and other HPV infection types $(6,11,40,42,43,44,54,61$ and 70). The amplification of the human housekeeping gene as an endogenous internal control will be used in order to monitor nucleic acid isolation and check for possible PCR inhibition. The protocol will be performed as recommended by the manufacturer (Seegene, Seoul, South Korea) using the CFX96 real-time PCR instrument (Bio-Rad, Schönenbuch, Switzerland) provided with the Novaplex II HPV28 test.

\section{Results of HPV testing}

Participants will have access to an external web page where they will be able to find information about their results which will be protected by a password provided during the interview. In cases of no infection or infection with a low-risk HPV type, participants will be informed of the negative genital results. Conversely, participants infected with high-risk HPV types will be advised to return to primary care units or centres for testing and counselling to be informed about the result. These individuals will be oriented about the meaning of the result and instructed about follow-up according to national guidelines. Participants with a suggestive lesion of HPV as well as participants with positive tests for HIV or syphilis will follow the protocol of each primary care unit.

\section{Data analyses and statistics}

The data analysis will use statistical methods appropriate for data collected with a complex sampling design. The analyses will consider the dependence among observations (homophily within networks) resulting from the recruitment chains, and the unequal probabilities of selection resulting from the different network sizes of each participant. The social network size of each participant will be used to apply statistical weights to mitigate biases due to differential network sizes, where those with larger network sizes have a smaller probability of selection and vice versa. ${ }^{19}$

Categorical variables will be summarised using absolute frequencies and percentages, while continuous variables will be analysed using means and SD. $\chi^{2}$ tests and Fisher's exact tests will be used to compare proportions and t-tests or the Mann-Whitney non-parametric tests will be used to compare continuous variables. The association between HPV infection, and social and behavioural variables will be defined by calculating crude and adjusted prevalence ratios using a modified Poisson regression analysis. A sensitivity analysis will be performed by type of included population. To calculate a single nationwide HPV prevalence, the data from all capitals will be merged and analysed with RDS Analyst and Statistical Analysis System software (SAS Institute) V.9.4.

\section{Monitoring and quality control}

The data quality will be validated by routine practices. A pilot study will be conducted among 20 sex workers and $20 \mathrm{MSM}$ in at least two Brazilian capitals ${ }^{23}$ to identify and correct problems in data collection, sample transportation, procedures and instruments. All health professionals involved in the research will be trained and certified by the coordinator team using simulated interviews. Data entry will be performed during the interviews by these trained health professionals and will be monitored by the main research team in Porto Alegre.

Coupons and study IDs will be managed through a web-based platform developed as part of the data entry programme. The same platform will be used for interviews, biological sample information, study process control and feedback to healthcare professionals involved in the study.

Data and specimen collection will be periodically evaluated by reports generated by the data programme, including information about the number of participants, the number of refusals and the quality of the samples collected. Those reports will be distributed monthly to all health professionals involved in data acquisition.

Moreover, each unit will receive at least one in one monitoring visit which will be performed by research staff supervisors to evaluate protocol compliance and provide 
recertification. Supervisors will observe techniques using predefined check lists and recorded interviews.

To access the reliability of the interviews, a subsample will be obtained in duplicate. A resampling will be performed in $10 \%$ of the interviews using phone calls or online forms to access the coefficient of agreement and systematic differences between data. ${ }^{24}$

\section{Study status}

The SMESH study is at an early stage. The pilot study is ongoing, starting in June 2019 in two capitals of Brazil: Porto Alegre and João Pessoa, located in the southern and northeastern parts of the country, respectively. Data collection at other sites is expected to start by the end of 2019 and to be completed in the following year.

\section{Patient and public involvement}

We met with sex workers and members of MSM communities to vet the name of the project, to explore sex and gender identities, to gather suggestions on study sites, to assess the willingness to participate and provide a biological specimen, to determine the appropriate language for the survey instrument and to ensure that all procedures were sensitive to the needs of the participants.

\section{DISCUSSION}

Despite the common aetiological role of HPV in the development of several cancers, there is insufficient epidemiological data among sex workers and MSM. Surveys on this topic must to be comprehensive and encompass all possible confounding factors to elucidate HPV transmission between different body sites and populations.

It is difficult to investigate the factors that drive the transmission of infectious diseases in hidden or hard-toreach population subgroups by using commonly used epidemiological methods of data collection because of the lack of an adequate sampling frame. ${ }^{25}$ As a result, traditional survey methods are often ineffective or cost prohibitive for sampling these populations.

Since its introduction in 1997, the RDS methodology has been widely used in surveys of hidden or hard-toreach populations using. ${ }^{25} 26$ Although often efficient, the RDS method has some limitations. A sample selected through RDS is a product of a series of both theoretical assumptions and operational issues, such as seed selection, logistics and control of 'masking'. Although this method can easily and rapidly identify numerous participants, the observations are not independent. Sampling occurs through pre-existing relationships and is prone to sampling biases because not everyone has an equal probability of selection, so this probability is typically estimated using a combination of modelling assumptions and study data. ${ }^{25}$ Until better methods are available, RDS will continue to be used to provide population estimates of hard-to-reach populations.

The epidemiology of HPV infection in sex workers and MSM in Brazil has been scarcely studied. Two studies among female sex workers used the RDS method; however, one did not evaluate HPV, ${ }^{27}$ and the other analysed HPV among female sex workers but had a limited sample and restricted HPV types. ${ }^{28}$ Among MSM, Szwarcwald et $a l^{29}$ conducted a large study but was limited to Brazilian military conscripts, while Ferreira $e t a l^{30}$ analysed a sample of MSM drug users but did not focus on HPV prevalence. The HPV in Men (HIM) study was designed to assess HPV type distribution but only among men residing in São Paulo. ${ }^{31}$

The HPV vaccination is an opportunity to prevent associated HPV lesions and cervical cancer. However, in Brazil, the HPV immunisation programme using the quadrivalent (types 6, 11, 16and 18) vaccine introduced as a public strategy in 2014 is currently applied only to girls (9-14 years old), boys (11-14 years old) and priority groups living with HIV/AIDS, recipients of solid organs transplants, bone marrow recipients and cancer patients (9-26 years old). ${ }^{32}$ Given the relatively recent introduction of routine HPV vaccination recommendations, it is less likely that participants will have received a vaccination series. Many participants are likely to be outside the age range recommended for HPV vaccines, and they may also have had difficulty accessing the immunisation programme or even lack of knowledge about the vaccine. ${ }^{32}$

In some countries, vaccine recommendations have been extended to include specific high-risk groups. In the USA, the HPV vaccine is recommended for individuals aged 9-26 years with immunocompromising conditions that may reduce cell-mediated or humoral immunity, for MSM, for transgender persons aged 9-26 years, for individuals not adequately vaccinated and, children with a history of sexual abuse. ${ }^{33}$ In Canada, individuals with abnormal cervical cytology or a history of cervical cancer and/or genital warts, MSM and immunocompromised individuals are included. ${ }^{34}$ In Australia, MSM, sex industry workers and immunocompromised individuals are included ${ }^{35}$; this is the first country in which cervical cancer could be eliminated within the next two decades. ${ }^{36}$

The potential benefits of offering HPV vaccines to individuals with a high pre-exposure likelihood remain unclear. Both men and women sex workers are at high risk for HPV. Women with disease caused by HPV may still benefit from vaccination, and the vaccine can prevent transmission to sexual partners. ${ }^{37}$ On the other hand, current vaccines do not affect current HPV infections and likely have no effect on latent infections. ${ }^{37}$ Moreover, little is known about HPV and the vaccine from the perspective of the population of interest. ${ }^{38}$

Due to the literature gap on the prevalence of HPV and the sexual health of MSM and sex workers in Brazil as well as the intense stigma surrounding these populations, a critical analysis of the study results will contribute to epidemiological knowledge and will be useful for the development of coping strategies for virus morbidities. The SMESH study may support health policies related to HPV vaccination in high-risk groups. 


\section{Limitations}

Although this study will include all Brazilian geographical regions, it will not include all capitals of Brazil and will limit restrain the sampling to state capitals for logistical reasons. It may be difficult to access the entire spectrum of the population of sex workers, including high-level and club workers. Additionally, the sampling is sensitive in the selection of the seeds which could also lead to the inclusion of specific groups in each city and fail to represent the entire population of the state capital or even the state.

\section{ETHICS AND DISSEMINATION}

Individuals must voluntarily agree to participate and must sign the free and informed consent form. The study follows the ethical recommendations of Resolutions $347 / 05,441 / 11$ and 466/12 of the National Health Council. Preliminary results will be presented as a poster presentation and/or in oral presentations at national and international congresses, and the final results will be submitted for publishing in peer-reviewed open-access journals. The results will also be presented in a personal meeting to the Ministry of Health of Brazil, which is a partner in the development of this project, and the information can be used to plan public strategies for STI and HPV infection reduction. Finally, we intend to publish a booklet aimed at the target participants of the study to convey the information we find.

Contributors EMW conceived the project and participated in all phases of the manuscript preparation; NLK, MB, JDCH and FF participated in the protocol development and helped write the manuscript; MB participated in the data analyses and statistics; JC participated in the laboratory protocol development. All authors reviewed the final version of the manuscript, with GFMP, FMAdS, CD and AGKM primarily responsible for revising the drafts for publication. The corresponding author had full access to all data in the study and had the final responsibility for the decision to submit the study publication.

Funding This work is financed by Hospital Moinhos de Vento through the Institutional Development Support Program of the Brazilian National Health System (PROADI-SUS), supported by the Ministry of Health of Brazil.

Disclaimer The funders of the study had no role in the study design, data collection, data analysis, data interpretation or report writing.

Competing interests None declared.

Patient consent for publication Not required.

Ethics approval This project was approved by the research ethics committee of the proposing institution (Hospital Moinhos de Vento, number 2.837.840).

Provenance and peer review Not commissioned; externally peer reviewed.

Open access This is an open access article distributed in accordance with the Creative Commons Attribution Non Commercial (CC BY-NC 4.0) license, which permits others to distribute, remix, adapt, build upon this work non-commercially, and license their derivative works on different terms, provided the original work is properly cited, appropriate credit is given, any changes made indicated, and the use is non-commercial. See: http://creativecommons.org/licenses/by-nc/4.0/.

ORCID iD

Natalia Luiza Kops http://orcid.org/0000-0002-3807-182X

\section{REFERENCES}

1 Bray F, Ferlay J, Soerjomataram I, et al. Global cancer statistics 2018: GLOBOCAN estimates of incidence and mortality worldwide for 36 cancers in 185 countries. CA Cancer J Clin 2018;68:394-424.
2 Torre LA, Islami F, Siegel RL, et al. Global cancer in women: burden and trends. Cancer Epidemiol Biomarkers Prev 2017;26:444-57.

3 Van Dyne EA, Henley SJ, Saraiya M, et al. Trends in human Papillomavirus-associated cancers - United States, 1999-2015. MMWR Morb Mortal Wkly Rep 2018;67:918-24.

4 Ryndock EJ, Meyers C. A risk for non-sexual transmission of human papillomavirus? Expert Rev Anti Infect Ther 2014;12:1165-70.

5 Vorsters A, Cornelissen T, Leuridan E, et al. Prevalence of high-risk human papillomavirus and abnormal Pap smears in female sex workers compared to the general population in Antwerp, Belgium. BMC Public Health 2016;16:477.

6 Somia IKA, Teeratakulpisarn N, Jeo WS, et al. Prevalence of and risk factors for anal high-risk HPV among HIV-negative and HIV-positive MSM and transgender women in three countries at south-east Asia. Medicine 2018;97:e9898.

7 Fairley $\mathrm{CK}$, Zou H, Zhang L, et al. Human papillomavirus vaccination in men who have sex with men - what will be required by 2020 for the same dramatic changes seen in heterosexuals. Sex Health 2017; $14: 123-5$.

8 Brasil, Ministério da Saúde, Secretaria de Vigilância em Saúde. Departamento de Vigilância, Prevenção E Controle das Infecções Sexualmente Transmissíveis, do HIVIAIDS E das Hepatites Virais. agenda Estratégica para Ampliação do Acesso E Cuidado integral das Populações-Chave em HIV, Hepatites Virais E outras Infecções Sexualmente Transmissíveis/Ministério dA Saúde. Secretaria de Vigilância em Saúde. Departamento de Vigilância, Prevenção $E$ Controle das Infecções Sexualmente Transmissíveis, do HIVIAIDS E das Hepatites Virais - Brasília: Ministério dA Saúde, 2018: 36.

9 Velazquez-Hernandez N, Sanchez-Anguiano LF, Guerra-Infante FM, et al. Human papillomavirus infection in female sex workers: a case control study. J Clin Med Res 2019;11:196-201.

10 Hooi DJ, Quint WGV, Lissenberg-Witte BI, et al. Human papillomavirus (HPV) types prevalence in cervical samples of female sex-workers on Curaçao. Prev Med Rep 2018;11:120-4.

11 Marra E, Kroone N, Freriks E, et al. Vaginal and anal human papillomavirus infection and seropositivity among female sex workers in Amsterdam, the Netherlands: prevalence, concordance and risk factors. $J$ Infect 2018;76:393-405.

12 Soohoo M, Blas M, Byraiah G, et al. Cervical HPV infection in female sex workers: a global perspective. Open AIDS J 2013;7:58-66.

13 Lugo LZA, Jacob CMB, Machado AP, et al. Human papillomavirus and coinfections with Chlamydia trachomatis, Gardnerella vaginalis, and Trichomonas vaginalis in self-collected samples from female sex workers in the Central-Western region of Brazil. J Bras Patol E Med Lab 2018;54:46-51.

14 Clatts MC, Goldsamt LA, Giang LM, et al. Sexual practices, partner concurrency and high rates of sexually transmissible infections among male sex workers in three cities in Vietnam. Sex Health 2015;12:39-47.

15 Baral SD, Friedman MR, Geibel S, et al. Male sex workers: practices, contexts, and vulnerabilities for HIV acquisition and transmission. Lancet 2015;385:260-73.

16 D'Souza G, Wiley DJ, Li X, et al. Incidence and epidemiology of anal cancer in the Multicenter AIDS cohort study. J Acquir Immune Defic Syndr 2008;48:491-9.

17 Daling JR, Madeleine MM, Johnson LG, et al. Human papillomavirus, smoking, and sexual practices in the etiology of anal cancer. Cancer 2004;101:270-80.

18 Goldstone S, Palefsky JM, Giuliano AR, et al. Prevalence of and risk factors for human papillomavirus (HPV) infection among HIV-seronegative men who have sex with men. $J$ Infect Dis 2011;203:66-74.

19 World Health Organization. Introduction to HIV/AIDS and sexually transmitted infection surveillance: module 4: introduction to respondent-driven sampling, 2013. Available: http://www.who.int/iris/ handle/10665/116864 [Accessed 22 Apr 2019].

20 Centers for Disease Control and Prevention. National health and nutrition examination survey (NHANES).HPV rinse, 2016. Available: https://wwwn.cdc.gov/Nchs/Nhanes/2013-2014/ORHPV_H.htm [Accessed 22 Apr 2019].

21 Meites E, Gorbach PM, Gratzer B, et al. Monitoring for human papillomavirus vaccine impact among gay, bisexual, and other men who have sex with Men-United states, 2012-2014. J Infect Dis. 2016;214:689-96.

22 Zacaronn V. Telelab. Diagnóstico e monitoramento. Testes Rápidos - Acesso rápido. Available: https://telelab.aids.gov.br/index.php/ component/k2/item/769 [Accessed 22 Apr 2019].

23 Hertzog MA. Considerations in determining sample size for pilot studies. Res Nurs Health 2008;31:180-91.

24 McMillan GP, Hanson TE. Sample size requirements for establishing clinical test-retest standards. Ear Hear 2014;35:283-6. 
25 White RG, Hakim AJ, Salganik MJ, et al. Strengthening the Reporting of Observational Studies in Epidemiology for respondent-driven sampling studies: "STROBE-RDS" statement. J Clin Epidemiol 2015;68:1463-71.

26 Gios L, Mirandola M, Sherriff N, et al. Being in the closet. correlates of Outness among MSM in 13 European cities. J Homosex 2019:1-19.

27 Dourado I, Guimarães MDC, Damacena GN, et al. Sex work stigma and non-disclosure to health care providers: data from a large RDS study among FSW in Brazil. BMC Int Health Hum Rights 2019;19:8.

28 Baldin-Dal Pogetto MR, Silva MG, Parada CMGdeL. Prevalence of sexually transmitted diseases in female sex workers in a City in the interior of São Paulo, Brazil. Rev Lat Am Enfermagem 2011;19:493-9.

29 Szwarcwald CL, Andrade CLTde, Pascom ARP, et al. Hiv-Related risky practices among Brazilian young men, 2007. Cad. Saúde Pública 2011;27:s19-26.

30 Ferreira AD, Caiaffa WT, Bastos FI, et al. Profile of male Brazilian injecting drug users who have sex with men. Cad. Saúde Pública 2006;22:849-60.

31 Liu Z, Nyitray AG, Hwang L-Y, et al. Acquisition, persistence, and clearance of human papillomavirus infection among male virgins residing in Brazil, Mexico, and the United States. J Infect Dis 2018;217:767-76.

32 Brasil, Ministério da Saúde. Informe técnico dA ampliação dA oferta das vacinas papilomavírus humano $6,11,16$ E 18 (recombinante) - vacina HPV quadrivalente E meningocócica C (conjugada), 2018. Available: http://portalarquivos2.saude.gov.br/images/pdf/2018/marco/14/InformeT-cnico-HPV-MENINGITE.pdf [Accessed 22 Apr 2019].

$33 \mathrm{Kim}$ DK, Hunter P. Advisory Committee on immunization practices recommended immunization schedule for adults aged 19 years or older - United States, 2019. MMWR Morb Mortal Wkly Rep 2019;68:115-8

34 Canada PHA of. update on the recommended human papillomavirus (HPV) vaccine immunization schedule, 2016. Available: https://www. canada.ca/en/public-health/services/publications/healthy-living/ update-recommended-human-papillomavirus-vaccine-immunizationschedule.html [Accessed 22 Apr 2019].

35 Health AGD of. Vaccination for other groups. Aust Immun Handb, 2018. Available: https://immunisationhandbook.health.gov.au/ vaccination-for-special-risk-groups/vaccination-for-other-groups [Accessed 22 Apr 2019].

36 Hall MT, Simms KT, Lew J-B, et al. The projected timeframe until cervical cancer elimination in Australia: a modelling study. Lancet Public Health 2019;4:e19-27.

37 Schim van der Loeff MF, Vorsters A, Marra E, et al. Should female sex workers be offered HPV vaccination? Hum Vaccin Immunother 2019;15:1544-8.

38 Brown B, Cabral A. Letter to the editor: female sex workers and HPV vaccine. Hum Vaccin Immunother 2019:1-2.
39 IBGE. Pesquisa Nacional por Amostra de Domicílios Contínua PNAD, 2017. Available: https://ww2.ibge.gov.br/home/estatistica/ pesquisas/pesquisa_resultados.php?id_pesquisa=149 [Accessed 22 Apr 2019].

40 Brasil, Ministério da Saúde. Secretaria de Vigilância em Saúde. Departamento de Vigilância, Prevenção e Controle das IST, do HIV/ Aids e das Hepatites Virais. Pesquisa de Conhecimentos, Atitudes e Práticas na População Brasileira - PCAP 2013, 2011. Available: http://www.aids.gov.br/pt-br/pub/2016/pesquisa-de-conhecimentosatitudes-e-praticas-na-populacao-brasileira-pcap-2013 [Accessed 22 Apr 2019].

41 Brasil, Ministério da Saúde. Secretaria de Vigilância em Saúde. Programa Nacional de DST e AIDS. Pesquisa entre Conscritos do Exército Brasileiro 1996-2002: Retratos do comportamento de risco do jovem brasileiro infecção pelo HIV / Ministério dA Saúde, Secretaria de Vigilância em Saúde, Programa Nacional de DST E AIDS. Brasília: Ministério da Saúde, 2006.

42 ABEP. Associação Brasileira de Empresas de Pesquisa. Critério Brasil, 2018. Available: http://www.abep.org/criterio-brasil [Accessed 22 Apr 2019].

43 Centers for Disease Control and Prevention. Smoking and tobacco use. National health and nutrition examination survey. questionnaire instruments, 2017. Available: https://wwwn.cdc.gov/nchs/data/ nhanes/2017-2018/questionnaires/SMQ_J.pdf [Accessed 22 Apr 2019].

44 Henrique IFS, De Micheli D, Lacerda RBde, et al. Validação dA versão brasileira do teste de triagem do envolvimento CoM álcool, cigarro E outras substâncias (assist). Rev Assoc Med Bras 2004;50:199-206.

45 Humeniuk R, World Health Organization. The alcohol, smoking and substance involvement screening test (assist): manual for use in primary care. Geneva: World Health Organization, 2010.

46 Vanderpool RC, Williams CM, Klawitter AR, et al. Effective dual method contraceptive use and HPV vaccination among U.S. adolescent and young adult females. Womens Health Issues 2014;24:543-50.

47 Brasil, Ministério da Saúde. Vigitel Brasil 2016 Saúde Suplementar: vigilância de fatores de risco e proteção para doenças crônicas por inquérito telefônico [recurso eletrônico] / Ministério da Saúde, Agência Nacional de Saúde Suplementar, 2017. Available: http:// bvsms.saude.gov.br/bvs/publicacoes/vigitel_brasil_2016_saude suplementar.pdf [Accessed 22 Apr 2019].

48 Hutz CS, Zanon C. Revision of the adaptation, validation, and normatization of the Roserberg self-esteem scale. Aval psicol 2011;10.

49 Waller J, Ostini R, Marlow LAV, et al. Validation of a measure of knowledge about human papillomavirus (HPV) using item response theory and classical test theory. Prev Med 2013;56:35-40. 